\title{
Taraxacum farinosum Hausskn. \& Bornm. bitkisinin antioksidan aktivite yönünden incelenmesi*
}

\section{Investigation of antioxidant activity of the plant Taraxacum farinosum Hausskn. \& Bornm}

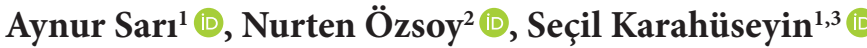

\footnotetext{
* 28 Mayıs-1 Haziran 2014 XXI. Bitkisel İlaç Hammaddeleri Toplantısı, Erciyes Üniversitesi Eczacllık Fakültesi, Ürgüp: Bildiri Kitabı’nda poster özeti olarak basılmıştır.
}

İstanbul Üniversitesi, Eczacllık Fakültesi, ${ }^{1}$ Farmakognozi Anabilim Dal,,${ }^{2}$ Biyokimya Anabilim Dal, İstanbul, Türkiye

${ }^{3}$ Çukurova Üniversitesi, Eczacılık Fakültesi, Farmakognozi Anabilim Dall, Adana, Türkiye

ORCID: A.S. 0000-0001-8116-7053;

N.Ö. 0000-0002-2419-9128;

S.K. 0000-0002-3515-2974

Sorumlu yazar/Corresponding author:

Aynur Sar1,

İstanbul Üniversitesi, Eczacılık Fakültesi, Farmakognozi Anabilim Dalı, İstanbul, Türkiye

E-posta: aynur@istanbul.edu.tr

Başvuru/Submitted: 06.01.2020

Kabul/Accepted: 06.02.2020

Atıf/Citation: Sari A, Ozsoy N, Karahuseyin S. Investigation of antioxidant activity of the plant taraxacum farinosum Hausskn. \& Bornm.. Sağlık Bilimlerinde İleri Araştırmalar Dergisi 2020; 3(1) 13-19.

https://doi.org/10.26650/ARHS2020-670992
ÖZ

Taraxacum Wigg. cinsi Asteraceae familyasının bir üyesidir. Bu cins Türkiyede yaklaşık 49 tür ile temsil edilmektedir. Taraxacum türleri halk arasında diüretik olarak, dispepsi, reflü, dalak ve karaciğer rahatsızlıkları, anoreksiya gibi çeşitli hastalıkların tedavisinde kullanılır. Taraxacum türlerinden seskiterpen laktonlar, triterpenler, fitosteroller, flavonoitler, lignanlar, kumarinler, fenolik asitler, beta-karbolin alkaloitleri, indol alkaloitleri, karotenoidler grubundan bileşikler elde edildiği rapor edilmiștir. Bu çalışmada Türkiye için endemik bir tür olan Taraxacum farinosum Hausskn. \& Bornm. bitkisinin kök ve toprak üstü kısımlarından elde edilen metanol ekstrelerinin etil asetat ve kloroform fraksiyonları total fenolik bileşik miktarları ve antioksidan potansiyelleri bakımından incelenmiştir. En yüksek total fenolik bileşik miktarı ve antioksidan aktivitenin etil asetat fraksiyonlarında olduğu saptanmıştır.

Anahtar Kelimeler: Taraxacum farinosum, antioksidan, aktivite, kök, toprak üstü

\section{ABSTRACT}

The genus Taraxacum Wigg. is a member of the family Asteraceae. This genus is represented by about 49 species in Turkey. Taraxacum species are commonly used as a diuretic and for the treatment of various diseases such as dyspepsia, reflux, spleen and liver disorders, and anorexia. Compounds from the group of sesquiterpene lactones, triterpenes, phytosterols, flavonoids, lignans, coumarins, phenolic acids, beta-carboline alkaloids, indole alkaloids, and carotenoids have been reported from Taraxacum species. In this study, ethyl acetate and chloroform fractions of methanol extract obtained from root and aerial parts of Taraxacum farinosum Hausskn. \& Bornm., an endemic species to Turkey, were investigated in terms of total phenol compound amounts and antioxidant potentials. The highest total phenolic compounds and antioxidant activity were determined in ethyl acetate fractions.

Keywords: Taraxacum farinosum, antioxidant, activity, root, aerial parts 


\section{GİRIŞ}

Dünya Sağllk Örgütü (WHO)'ne göre "tıbbi bitki”; organlarından birinin veya daha fazlasının, terapötik amaçlar için ya da başka ilaçların sentezinde öncül olarak kullanılabilecek maddeleri içeren herhangi bir bitkidir (24). Bu tanım, bileşenleri ve tedavi edici özellikleri bilimsel olarak kurulan ve tıbbi olarak kabul edilmesine rağmen henüz bilimsel olarak çalışılmamış olan bitkileri birbirinden ayırır (13). Bunlar arasında karahindiba (Taraxacum türleri) 2500' den fazla türü rapor edilen yaygın bir tıbbi bitkidir (11). Bu türlerin bir kısmı, Taraxacum officinale ve Taraxacum erythrospermum olarak dünya çapında yaygın olarak dağılmış olarak bulunur, ancak günümüzde sadece küçük bir kısmı bilimsel olarak incelenmiştir (13).

Taraxacum cinsine ait bitkiler uzun zamandan beri tıbbi bitki olarak kullanılmaktadır. Taraxacum; Yunanca "taraxis" iltihap ve "akeomai" tedavi kelimelerinden oluşur. İngilizce’ de “dandelion” olarak isimlendirilen "karahindiba" bitkisi, bu ismini dişli yapraklarından dolayı Fransızca' daki "dent-de-lion" (aslan dişi) kelimelerinden alır. Fransızca' da bu bitki diüretik etkisinden dolayı "altı ıslatan" (pissenlit) olarak isimlendirilmiştir (19).

Karahindiba bitkisinin geleneksel tedavide ilk kullanımı 10. ve 11. yüzyıllara dayanmaktadır. Arap doktorları tarafından karaciğer ve dalak rahatsızlıklarında kullanılmıştır. Kuzey Amerika yerlileri tarafından ise bitkinin kök ve toprak üstü kısımlarından elde edilen infüzyon ve dekoksiyonlar böbrek hastalı̆̆ı, dispepsi ve mide ekşimesinde kullanılmıştır. Karahindiba, Çin tıbbında geleneksel olarak genelde başka bitkilerle karıştırılarak üst solunum yolu enfeksiyonları, hepatit, bronşit ve pnömonide kullanılmış$\operatorname{tır}(13,19)$. Ülkemizde ise halk arasında hafif müshil, laksatif, safra söktürücü, diüretik ve antidiyabetik olarak kullanılışı vardır $(1,15)$. Taraxacum türlerinden hazırlanan infüzyon İç Anadolu'da spazm giderici olarak kullanılmakta ve ağrı kesici olarak tüketilmektedir (16).

Kuzey yarımkürede yaygın olarak bulunan, özellikle bu yarımkürenin sıcak bölgelerinde geniş yayılış gösteren Taraxacum, Asteraceae familyasının Cichorioideae alt familyasından Lactuceae tribusuna ait bir üyesidir $(10,22)$. Karahindiba sapsız çok yıllık bir otsu bitkidir, yeşil yapraklar bitkinin tabanında kümelenmiş ve bütün bitki beyaz lateks içerir. Çiçek sapları sarı renkte çiçekler bulundurur. Karahindiba bitkisi derin köklüdür, yani bitkinin havadan kesilmiş bir şekilde kesildikten sonra bile yeni bir bitki üretme kabiliyeti vardır. Karahindiba, çiçeklenmeye başladığında yani ilkbahar ve sonbahar arasında hasat edilir (10).

Doğal olarak yetişen Taraxacum cinsine ait bitkiler ülkemizde 49 tür ve 54 taksonla temsil edilmektedir (22). Bunlardan biri olan Taraxacum farinosum Hausskn. \& Bornm. Türkiye'de genellikle Orta Anadolu'da yayılış göstermekte olup çok yıllık otsu bir bitkidir ve ülkemiz için endemik bir türdür (23).

Taraxacum türleri ile daha önce yapılan fitokimyasal çalışmalarda triterpenler, seskiterpen laktonlar, indol alkaloitleri, fitosteroller, flavonoitler, lignanlar, fenolik asitler, kumarinler, beta-karbolin alkaloitleri, karotenoidler gibi gruplardan çeşitli bileşikler elde edilmiştir $(5,10,12,13,19,20)$. Acı maddeler, fenoller ve fitosteroller dahil olmak üzere bazı fitokimyasallar, antioksidan ve antienflamatuar aktivitelere sahiptir (7).

Taraxacum türlerinin antioksidan özellikleri, çeşitli in vitro ve in vivo modellerde ortaya konmuştur. Kökten çiçeğe kadar, karahindiba türlerinin farklı kısımları çeşitli antioksidan potansiyele sahipken, yaprak ekstresi kök ekstresinden daha güçlü bir hidrojen bağışlama kapasitesi sergiler (10).

Bu çalışmada ülkemizde endemik tür olarak yetişen Taraxacum farinosum Hausskn. \& Bornm. bitkisinin toprak üstü ve kök metanol ekstrelerinden elde edilen etil asetat ve kloroform fraksiyonlarının antioksidan aktiviteleri incelenmiştir.

\section{MATERYAL VE METOT}

\section{Bitki Materyali}

Taraxacum farinosum Hausskn. \& Bornm. bitkisi 21.08.2004 tarihinde Kayseriden toplanmıştır. İstanbul Üniversitesi Eczacıllk Fakültesi Herbaryumu' nda (ISTE) 81946 numarası ile kayıtlıdır.

\section{Ekstraksiyon}

Bitkinin toprak üstü (TÜ) (50 gram) ve kök (K) (50 gram) kısımları laboratuvar ortamında gölgede 
Tablo 1. T. farinosum türünün toprak üstü ve kök kısımlarından hazırlanan etil asetat ve kloroform fraksiyonlarının içerdikleri total fenolik maddelerin (PC, bitki ağırlığının her gramı için gallik asit ekivalanı olarak) ve flavonoit (bitki ağırlı̆̆ının her gramı için kateşin ekivalanı olarak) miktarları.

\begin{tabular}{|c|c|c|}
\hline Fraksiyon & $\begin{array}{c}\text { PC } \\
(\mathbf{m g} / \mathbf{g} \text { ekstre) }\end{array}$ & $\begin{array}{c}\text { Flavonoit } \\
\text { (mg/g ekstre) }\end{array}$ \\
\hline $\begin{array}{c}\text { Toprak üstü } \\
\text { etil asetat }\end{array}$ & $99,78 \pm 0,84^{\mathrm{a}}$ & $101,61 \pm 0,65^{\mathrm{a}}$ \\
\hline Toprak üstü kloroform & $40,50 \pm 0,58^{\mathrm{b}}$ & $33,58 \pm 1,82^{\mathrm{b}}$ \\
\hline $\begin{array}{c}\text { Kök } \\
\text { etil asetat }\end{array}$ & $105,43 \pm 3,3^{\mathrm{a}}$ & $104,98 \pm 4,36^{\mathrm{a}}$ \\
\hline $\begin{array}{c}\text { Kök } \\
\text { kloroform }\end{array}$ & $35,58 \pm 0,94^{\mathrm{b}}$ & $34,90 \pm 2,30^{\mathrm{b}}$ \\
\hline
\end{tabular}

Veriler ortalama \pm standart sapma olarak verilmiştir. Aynı sütun içindeki farklı harfler verilerin anlamlı olarak farklı olduklarını göstermektedir.

kurutulmuş ve toz edilmiştir. Ardından oda isısında metanol $(\mathrm{MeOH})$ ile masere edilerek solvent alçak basınç altında rotavaporda uçurulmuştur. Bakiye metanol/su (1:2) karışımında çözülüp sırasıyla petrol eteri, kloroform ve etil asetat ile tüketilerek fraksiyonlandırılmıştır. İşlem sonucunda toprak üstü kloroform fraksiyonu 0,285 gram, etil asetat fraksiyonu 0,417 gram; kök kloroform fraksiyonu 0,32 gram ve etil asetat fraksiyonu ise 0,294 gram olarak elde edilmiştir.

\section{Antioksidan Aktivite Tayini}

T. farinosum bitkisine ait toprak üstü ve kök k1simlarından hazırlanan kloroform ve etil asetat fraksiyonlarının total fenolik bileşiklerin miktarı Folin-Ciocalteu ayıracı kullanılarak yapılmıștır (21). Ekstrenin lipid peroksidasyonunu inhibe edici aktivitesi fosfatidilkolin (lesitin) den hazırlanan lipit lipozomları kullanılarak test edilmiştir (6). Lipit peroksidasyonunun son ürünü olan malondialdehit (MDA), tiyobarbitürik asit (TBA) metodu ile tayin edilmiştir (4). Total radikal antioksidan potansiyeli, DPPH radikal giderici aktivitesi, süperoksit anyonu giderici aktivitesi, redükleyici güç (FRAP deneyi) tayinleri yapılmıştır $(2,3,14,18)$.

\section{İstatiksel Değerlendirme}

Çalışma sonucunda elde edilen veriler ortalama \pm standart sapma olarak verilmiştir. Test edilen maddelerin arasındaki farkın değerlendirilmesinde Student's $\mathrm{t}$ testten yararlanılmıştır. Anlamlık sınırı olarak $\mathrm{p}<0,05$ kabul edilmiştir. Değişkenler arasındaki ilişki ise korelasyon analizi ile değerlendirilmiştir.

\section{BULGULAR}

T. farinosum türünün toprak üstü ve köklerinden elde edilen metanol ekstrelerinin etil asetat ve kloroform fraksiyonlarının içerdikleri total fenolik madde (PC) ve flavonoit miktarları Tablo 1' de, antioksidan aktivite sonuçları ise Tablo 2' de gösterilmiştir.

2,5 mg/ml konsantrasyonda T. farinosum toprak üstü kısmı (\% 84,96 $\pm 0,18)$ ve kök $(\% 83,93 \pm 2,27)$ etil asetat fraksiyonları ile toprak üstü kısmı (\% 75,20 $\pm 2,44)$ ve kök (\% 72,07 $\pm 0,20)$ kloroform fraksiyonlarının gösterdiği lipit peroksidasyonu inhibe edici aktiviteleri, kersetinin 0,08 mg/ml'de (\% 91,48 $\pm 0,07)$ gösterdiği aktiviteye yakın ( $p>0,05)$ olduğu saptanmıştır.

2,5 $\mathrm{mg} / \mathrm{ml}$ konsantrasyonda $T$. farinosum toprak üstü kısmı etil asetat $(\% 92,7 \pm 0,69)$ ve $5 \mathrm{mg} / \mathrm{ml}$ 'de toprak üstü kısmı kloroform $(86,24 \pm 0,68)$, kök etil

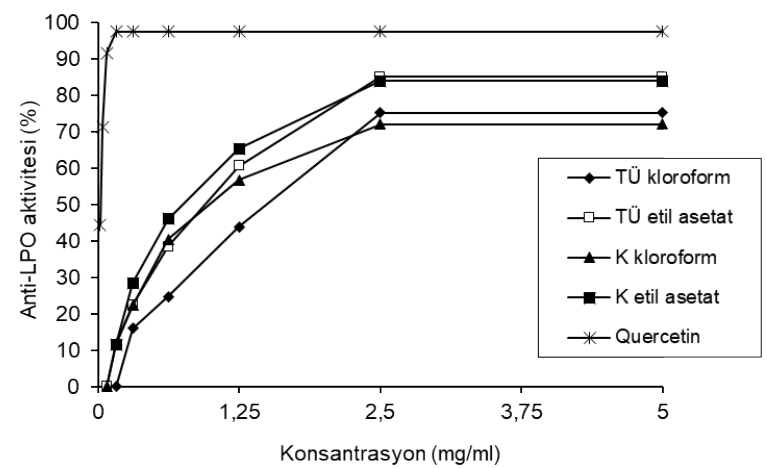

Şekil 1. T. farinosum toprak üstü kısmı ve köklerinden hazırlanan metanol ekstresinin fraksiyonlandırılması ile elde edilen kloroform ve etil asetat fraksiyonlarının lipit peroksidasyonu inhibe edici aktiviteleri. Kersetin standart olarak kullanılmıștır. Deneyler 3 kez tekrarlanarak değerlerin ortalamaları alınmıştır \pm SD $(n=3)$ 
Tablo 2. T. farinosum türünün toprak üstü ve kök kısımlarından hazırlanan etil asetat ve kloroform fraksiyonlarının ve standart olarak kullanılan kersetinin antioksidan aktiviteleri

\begin{tabular}{|c|c|c|c|c|c|c|}
\hline \multirow[t]{2}{*}{ Fraksiyon } & \multicolumn{4}{|c|}{$\begin{array}{c}\text { EC50 } \\
(\mathrm{mg} / \mathrm{ml})\end{array}$} & \multirow{2}{*}{$\begin{array}{c}\text { Total } \\
\text { Antioksidan } \\
\text { potansiyeli e* } \\
(\mathrm{mM} \text { TEAC/L) }\end{array}$} & \multirow{2}{*}{$\begin{array}{l}\text { FRAP değeri }{ }^{*} \\
(\mathrm{mM} \mathrm{Fe} 2+/ \mathrm{L})\end{array}$} \\
\hline & Anti-LPOa & SODb & DPPHc & ABTSd & & \\
\hline $\begin{array}{c}\text { Toprak üstü } \\
\text { etil asetat }\end{array}$ & $1,15 \pm 0,03^{\mathrm{a}}$ & $1,31 \pm 0,04^{\mathrm{a}}$ & $0,93 \pm 0,07^{\mathrm{a}}$ & $1,81 \pm 0,10^{\mathrm{a}}$ & $2,13 \pm 0,02^{\mathrm{a}}$ & $2,73 \pm 0,01^{\mathrm{a}}$ \\
\hline $\begin{array}{l}\text { Toprak üstü } \\
\text { kloroform }\end{array}$ & $1,41 \pm 0,18^{\mathrm{a}}$ & $2,60 \pm 0,04^{\mathrm{b}}$ & $4,82 \pm 0,16^{\mathrm{b}}$ & $5,10 \pm 0,40^{\mathrm{b}}$ & $1,50 \pm 0,04^{\mathrm{b}}$ & $1,74 \pm 0,01^{\mathrm{b}}$ \\
\hline $\begin{array}{c}\text { Kök etil } \\
\text { asetat }\end{array}$ & $1,06 \pm 0,05^{\mathrm{a}}$ & $2,59 \pm 0,16^{\mathrm{b}}$ & $0,87 \pm 0,07^{\mathrm{a}}$ & $1,87 \pm 0,20^{\mathrm{a}}$ & $2,15 \pm 0,02^{\mathrm{a}}$ & $2,82 \pm 0,05^{\mathrm{a}}$ \\
\hline $\begin{array}{c}\text { Kök } \\
\text { kloroform }\end{array}$ & $1,36 \pm 0,06^{\mathrm{a}}$ & $2,71 \pm 0,05^{\mathrm{b}}$ & $4,30 \pm 0,26^{\mathrm{b}}$ & $5,57 \pm 0,33^{b}$ & $1,38 \pm 0,07^{\mathrm{b}}$ & $1,66 \pm 0,04^{\mathrm{b}}$ \\
\hline $\begin{array}{c}\text { Kersetin } \\
\text { (Quercetin) }\end{array}$ & $\begin{array}{l}0,035 \pm \\
0,002^{\mathrm{b}}\end{array}$ & $\begin{array}{l}0,461 \pm \\
0,014^{c}\end{array}$ & $\begin{array}{c}0,092 \pm \\
0,008^{c}\end{array}$ & $0,154 \pm 0,003^{c}$ & $2,09 \pm 0,27 * * a$ & $2,74 \pm 0,06 * * a$ \\
\hline \multicolumn{7}{|c|}{ 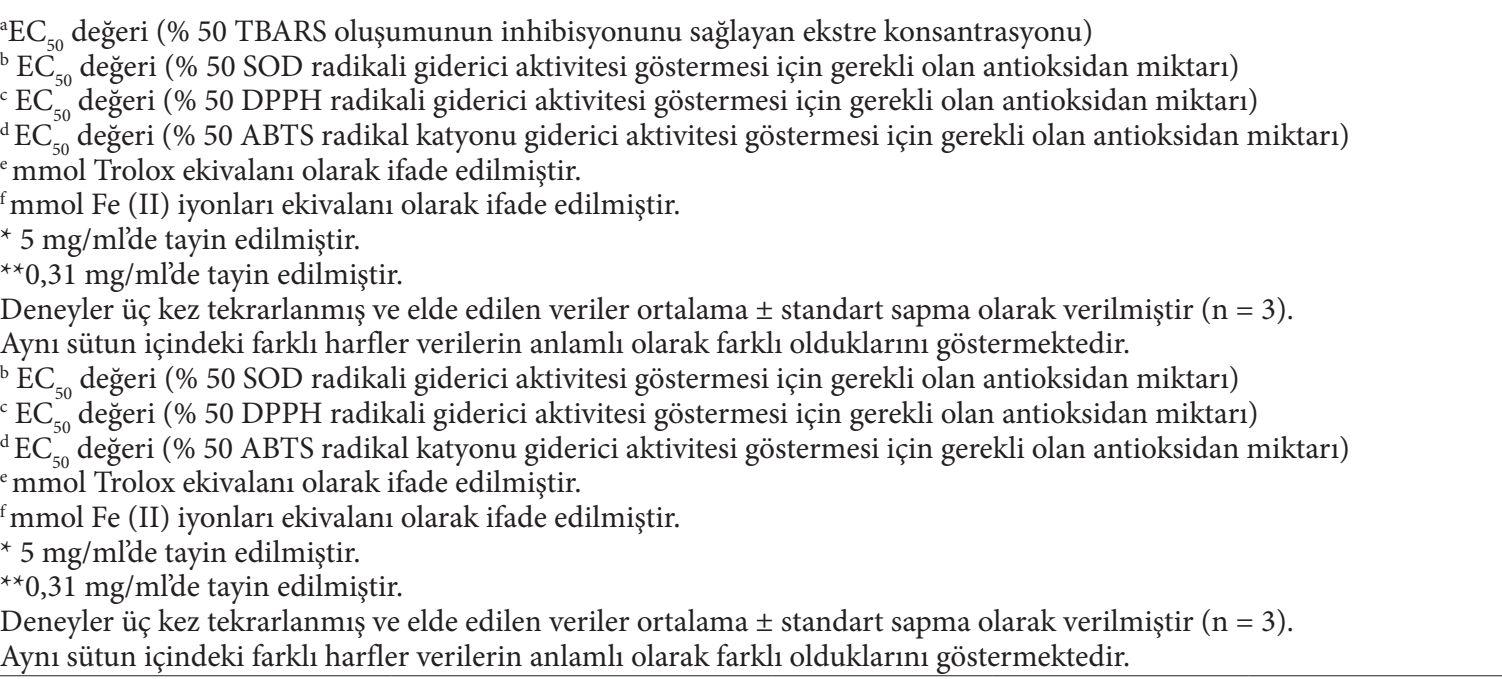 } \\
\hline
\end{tabular}

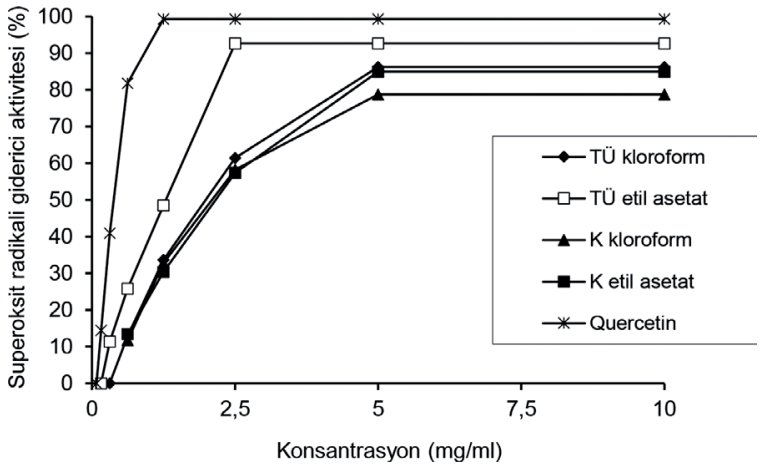

Şekil 2. T. farinosum toprak üstü kısmı ve köklerinden hazırlanan metanol ekstresinin fraksiyonlandırılması ile elde edilen kloroform ve etil asetat fraksiyonlarının süperoksit radikali giderici aktiviteleri. Kersetin standart olarak kullanılmıștır. Deneyler 3 kez tekrarlanarak değerlerin ortalamaları alınmıştır \pm SD $(n=3)$ asetat $(\% 84,97 \pm 0,51)$ ve kök kloroform $(\% 78,77 \pm$ $3,65)$ fraksiyonlarının gösterdiği süperoksit radikali giderici aktivitelerinin, kersetinin $0,625 \mathrm{mg} / \mathrm{ml}$ 'de (\% $81,81 \pm 1,24)$ gösterdiği aktiviteye yakın $(\mathrm{p}>0,05)$ olduğu saptanmıştır.

$2,5 \mathrm{mg} / \mathrm{ml}$ konsantrasyonda $T$. farinosum toprak üstü kısmı (\% 92,94 $\pm 2,37)$ ve kök (\% 93,79 $\pm 1,24)$ etil asetat fraksiyonlarının, $10 \mathrm{mg} / \mathrm{ml}$ 'de ise toprak üstü kısmı (\% 74,75 $\pm 3,27)$ ve kök (\% 90,01 $\pm 2,66)$ kloroform fraksiyonlarının gösterdiği DPPH radikali giderici aktivitelerinin, kersetinin $0,16 \mathrm{mg} / \mathrm{ml}$ 'de (\% 94,48 $\pm 2,31$ ) gösterdiği aktiviteye yakın ( $\mathrm{p}>0,05)$ olduğu saptanmıştır. 


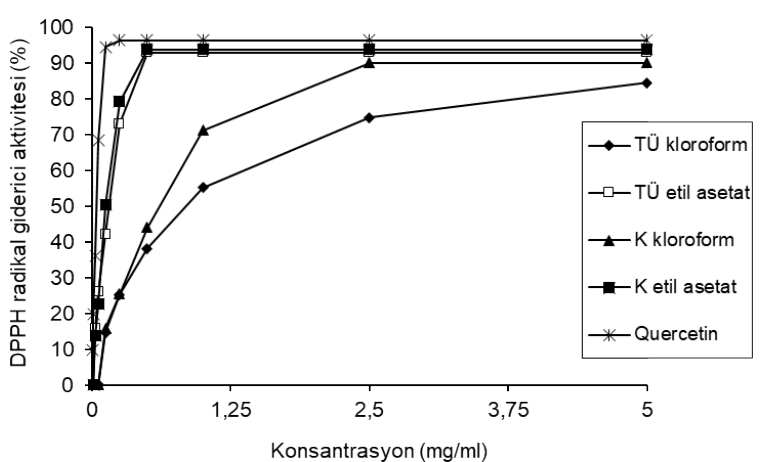

Şekil 3. T. farinosum toprak üstü kısmı ve köklerinden hazırlanan metanol ekstresinin fraksiyonlandırılması ile elde edilen kloroform ve etil asetat fraksiyonlarının DPPH radikali giderici aktiviteleri. Kersetin standart olarak kullanılmıștır. Deneyler 3 kez tekrarlanarak değerlerin ortalamaları alınmıştır \pm SD $(n=3)$

$5 \mathrm{mg} / \mathrm{ml}$ konsantrasyonda $T$. farinosum toprak üstü etil asetat (\% 90,65 $\pm 0,96)$ ve kök etil asetat (\% $91,53 \pm 1,0$ ) fraksiyonlarının, $20 \mathrm{mg} / \mathrm{ml}$ de ise toprak üstü kısmı kloroform (\% 91,49 $\pm 1,76)$ ve kök kloroform $(\% 92,10 \pm 0,23)$ fraksiyonlarının gösterdiği ABTS radikali giderici aktivitelerinin, kersetinin 0,31 $\mathrm{mg} / \mathrm{ml}$ 'de $(\% 91,84 \pm 0,31)$ gösterdiği aktiviteye yakın $(\mathrm{p}>0,05)$ olduğu saptanmıştır.

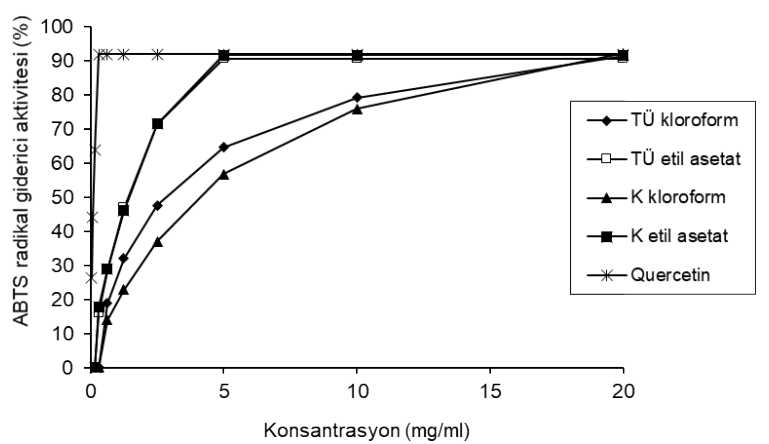

Şekil 4. farinosum toprak üstü kısmı ve köklerinden hazırlanan metanol ekstresinin fraksiyonlandırılması ile elde edilen kloroform ve etil asetat fraksiyonlarının ABTS radikali giderici aktiviteleri. Kersetin standart olarak kullanılmıștır. Deneyler 3 kez tekrarlanarak değerlerin ortalamaları alınmıştır \pm SD $(n=3)$

FRAP (Ferric Reducing Antioxidant Power) Deneyi

T. farinosum toprak üstü kısmı ve köklerinden hazırlanan metanol ekstresinin fraksiyonlandırılması ile elde edilen toprak üstü etil asetat (FRAP değe$\mathrm{ri}=2,82 \pm 0,053 \mathrm{mM} / \mathrm{L} \mathrm{Fe}^{2+}$ ) ve kök etil asetat (FRAP değeri $=2,73 \pm 0,008 \mathrm{mM} / \mathrm{L} \mathrm{Fe}^{2+}$ ) fraksiyonlarının 5 $\mathrm{mg} / \mathrm{ml}$ ' de gösterdikleri indirgeyici güçleri, kersetinin $0,31 \mathrm{mg} / \mathrm{ml}$ konsantrasyonunda gösterdiği yüksek indirgeyici güce (FRAP değeri $=2,74 \pm 0,06 \mathrm{mM} / \mathrm{L}$ $\mathrm{Fe}^{2+}$ ) yakın olduğu belirlenmiştir ( $\left.\mathrm{p}>0,05\right)$.

Yüksek FRAP değeri etil asetat fraksiyonlarının yüksek antioksidan aktiviteye sahip olduklarını göstermiştir.

\section{TARTIŞMA VE SONUÇ}

Bu çalışmada Taraxacum farinosum Hausskn. \& Bornm. türünün toprak üstü ve kök metanol ekstrelerinden elde edilen kloroform ve etil asetat fraksiyonlarının içerdikleri total fenolik madde ve flavonoit miktarları, indüklenmiş lipid peroksidasyonu inhibe edici, hidrojen atomu verici ve serbest radikal giderici etkileri ile indirgeyici güçleri tayin edilerek antioksidan etkileri incelenmiştir. Bu türden elde edilen toprak üstü ve kök etil asetat fraksiyonları arasında, ayrıca toprak üstü ve kök kloroform fraksiyonları arasında lipid peroksidasyon inhibisyonu şeklinde yansıyan antioksidan aktivitelerinde anlam1 farklılık gözlenmemiştir ( $\mathrm{p}>0,05)$. Bu sonuçlar; incelenen fraksiyonların etkili lipid peroksidasyon inhibitörleri olduklarını, peroksit radikallere hidrojen vererek onları zararsız hale getirebileceklerini ve radikal reaksiyonlarını sonlandırabileceklerini göstermektedir.

$\mathrm{EC}_{50}$ değerleri kıyaslandığında; toprak üstü ve kök etil asetat fraksiyonlarının DPPH, ABTS radikal katyonu giderici aktiviteleri ile redükleyici güçlerinin birbirine çok yakın olup toprak üstü ve kök kloroform fraksiyonlarının aktivitelerinden daha yüksek oldukları belirlenmiştir. Bu sonuçlar; etil asetat fraksiyonlarının daha etkili antioksidan olduklarını göstermektedir.

Bu çalışma sonucunda T. farinosum türünün fenolik bileşikler içerdiği, günümüze kadar geleneksel tedavide kullanılan Taraxacum cinsine ait ülkemizde endemik olarak bulunan bu türün antioksidan aktivite gösterdiği ilk kez ortaya konulmuştur.

Bu zamana kadar yapılan çalışmalar, Taraxacum bitkisinin farklı kısımları çeşitli antioksidan potansiyele sahipken, yaprak ekstresi kök ekstresinden daha güçlü bir hidrojen bağışlama kapasitesi sergilediğini göstermiştir (10). Polifenolik içeriği $(\% 9,9)$ ve flavo- 
noit içeriği $(\% 0,086)$, kök ekstrelerininkinden yaklaşı üç kat daha büyük olan yaprak ekstreleri, hidrojen bağış̧̧ıları, indirgeyici ajanlar ve hidrojen peroksit temizleyicileri olarak etkilidir $(7,8,9)$. Bu özellikler, yenidoğanlarda farklı tiplerde hiperbilirubinemi veya enzimopatilerin (örneğin, Crigler-Najjar sendromu ve Gilbert sendromu) tedavisi için ve ayrıca karaciğer anormallikleri, safra kesesi taşları ya da safra kesesi hastalıkları veya değişikliklerinin neden olduğu kolestaz tedavisi için kullanılmıştır $(7,17)$.

Hakem Değerlendirmesi: Dış bağımsız.

Peer Review: Externally peer-reviewed.

Yazar Katkıları: Çalışma Konsepti/Tasarım-A.S., N.Ö., S.K.; Veri Toplama- A.S., N.Ö., S.K; Veri Analizi/Yorumlama-N.Ö.; Yazı Taslağ1- A.S., N.Ö., S.K.; İçeriğin Eleştirel İncelemesi- A.S., N.Ö., S.K.; Son Onay ve Sorumluluk- A.S., N.Ö., S.K.; Malzeme ve Teknik Destek- A.S., N.Ö., S.K.; Süpervizyon- A.S.

Author Contributions: Conception/Design of Study- A.S., N.Ö., S.K.; Data Acquisition- A.S., N.Ö., S.K.; Data Analysis/Interpretation- N.Ö.; Drafting Manuscript- A.S., N.Ö., S.K.; Critical Revision of Manuscript- A.S., N.Ö., S.K.; Final Approval and Accountability- A.S., N.Ö., S.K.; Technical or Material Support- A.S., N.Ö., S.K.; Supervision- A.S.

Çıkar Çatışması: Yazarlar çıkar çatışması beyan etmemişlerdir.

Conflict of Interest: Authors declared no conflict of interest.

Finansal Destek: Yazarlar finansal destek beyan etmemişlerdir.

Financial Disclosure: Authors declared no financial support.

\section{KAYNAKLAR}

1. Baytop T. Türkiye'de Bitkilerle Tedavi, 1999. İstanbul: Nobel Tip Kitabevi.

2. Benzie IFF, Strain JJ. The ferric reducing ability of plasma (FRAP) as a measure of "antioxidant power": The FRAP assay, Analytical Biochemistry. 1996; 239:70-76.

3. Brand-Williams W, Cuvelier ME, Berset C. Use of a free radical method to evaluate antioxidant activity, Food Science and Technology.1995; 28:25-30.
4. Buege JA, Aust SD. (): Microsomal lipid peroxidation, Methods in Enzymology. 1978; 52:302-310.

5. Dai G. Dandelion. In: Wang, Y., Deng, W., Xue, C. (Ed.). Pharmacology and application of Chinese Material Medica. Beijing: People's Medical Publishing House. 1998: 1181-1186.

6. Duh PD, Tu YY, Yen GC. Antioxidant activity of water extract of Harng Jyur (Chrysanthemum morifolium Ramat), Food Science \&Technology. 1999; 32:269-277.

7. Gonzalez-Castejon M, Visioli F, Rodriguez-Casado A. Diverse biological activities of dandelion, Nutrition Reviews. 2012; 70(9): 534-547.

8. Hagymasi K, Blazovics A, Feher J, Lugasi A, Kristo Sz. $\mathrm{T}$, Kery A. The in vitro effect of dandelion's antioxidants on the microsomal lipid peroxidation, Phytother Res. 2000; $14: 43-4$

9. Hagymasi K, Blazovics A, Lugasi A, Kristo Sz. T, Feher J, Kery A. In vitro antioxidant evaluation of dandelion (Taraxacum officinale WEB.) water extracts, Acta Aliment. 2000; 29:1-7.

10. Hu C. Taraxacum: Phytochemistry and health benefits, Chinese Herbal Medicines. 2018; 10:353-61.

11. Kirschner J, Stepanek J. Clonality as part of the evaluation process in Taraxacum, Folia Geobotanica. 1994; 29(2):265-275.

12. Li C, Dong ZB, Jiang JL, Zhao WY. Determination of cichoric acid, caffeic acid, and chlorogenic acid in Taraxaci Herba by HPLC, Chinese Traditional Herbal Drugs. 2015; 46(23):3577-3580.

13. Martinez M, Poirrier P, Chamy R, Prüfer D, SchulzeGronover C, Jorquera L, Ruiz G. Taraxacum officinale and related species: An ethnoparmacological review and its potential as a commercial medicinal plant, J Ethnopharmacol. 2015; 169:244-62.

14. Nishikimi N, Rao NA, Yagi K. The occurrence of superoxide anion in the reaction of reduced phenazine methosulfate and molecular oxygen, Biochemi and Biophys Res Commun 1972; 46:849-54.

15. Önal S, Timur S, Okutucu B, Zihnioğlu F. Inhibition of alpha glucosidase by aqueous extract of some potent antidiabetic medicinal herbs, Preparative Biochemistry \& Biotechnology. 2005; 35:29-36. 
16. Özdemir E, Alpınar K. (): An ethnobotanical survey of medicinal plants in western part of central Taurus Mountains: Aladaglar (Nigde-Turkey), J Ethnopharmacol. 2015; 166:53-65.

17. Par A, Javor T. Alternatives in hepatoprotectioncytoprotection-influence on monooxygenase system free radical scavengers, Acta Physiologica Hungarica. 1984; 64:409-423.

18. Rice-Evans CA, Miller NJ, Paganga G. Antioxidant properties of phenolic compounds, Trends in Plant Science. 1997; 2:152-59.

19. Schütz K, Carle R, Schieber A. Taraxacum-A review on its phytochemical and pharmacological profile, J Ethnopharmacol, 2006; 107:313-23.

20. Shi SY, Zhou CX, Xu Y, Tao QF, Bai H, Lu FS, Lin WY, Chen HY, Zheng W, Wang LW, Wu YH, Zeng S, Huang KX, Zhao Y, Li X.K, Qu J. Studies on chemical constituents from herbs of Taraxacum mongolicum, Zhongguo Zhong Yao Za Zhi, 2008; 33(10):1147-57.
21. Slinkard K, Singleton VL. Total phenol analyses: automation and comparison with manual methods, Am J Enol Vitic. 1977; 28: 49-55.

22. Uysal A, Zengin G, Güneş E, Ekşinar Uysal N. Çerçeve kayması ve baz çifti değişimi mutasyonlarına karşı etkili doğal iki Taraxacum türü: Mutajenik, antimutajenik, antioksidan değerlendirme, Marmara Pharmaceutical Journal. 2016; 20:311-319.

23. Van Soest J.L. Taraxacum Wiggers. In: Davis, P.H. (Ed.). Flora of Turkey and the East Aegean Islands Vol.5, Edinburgh: University Press. 1975; 788-812.

24. WHO. Resolution-Promotion and Development of Training and Research in Traditional Medicine. 1978 Report No: 622. http://whqlibdoc.who.int/trs/WHO_ TRS_622.pdf 